\title{
Quantification of meteorological conditions for rockfall triggers in Central Europe
}

\author{
Katrin M. Nissen ${ }^{1}$, Stefan Rupp ${ }^{2}$, Thomas M. Kreuzer ${ }^{3}$, Björn Guse ${ }^{4}$, Bodo Damm², and Uwe Ulbrich ${ }^{1}$ \\ ${ }^{1}$ Institute for Meteorology, Freie Universität Berlin, Berlin, Germany \\ ${ }^{2}$ Institute for Applied Physical Geography, University of Vechta, Vechta, Germany \\ ${ }^{3}$ Institute for Geography and Geology, University of Würzburg, Würzburg, Germany \\ ${ }^{4} \mathrm{GFZ}$, German Research Centre for Geoscience, Potsdam, Germany
}

Correspondence: Katrin Nissen (katrin.nissen@met.fu-berlin.de)

\begin{abstract}
A rockfall dataset for Germany is analysed with the objective of identifying the meteorological and hydrological (pre-) conditions that change the probability for such events in Central Europe. The factors investigated in the analysis are precipitation amount and intensity, freeze-thawing cycles as well as sub-surface moisture. As there is no suitable observational dataset for all relevant sub-surface moisture types (e.g. water in rock pores and cleft water) available, simulated soil moisture and parameterised pore water are tested as substitutes. The potential triggering factors were analysed both for the day of the event as well as for the days leading up to the event.
\end{abstract}

It is found that the most important factor influencing rockfall probability in the research area is precipitation amount at the day of the event but the water content of the ground on that day and freeze-thawing cycles in the days prior to the event also influence the hazard probability. Comparing results with simulated soil moisture and parameterised pore water revealed that precipitation minus potential evaporation evaluated for a weekly period performs well as a proxy for the relevant sub-surface moisture types.

A logistic regression model was built, which considers individual potential triggering factors as well as their interactions. Using this model the effects of meteorological conditions on rockfall probability in the Central European low mountain ranges can be quantified. The model suggests that precipitation is most efficient, when the moisture content of the ground is high. An increase of daily precipitation from its local $50^{\text {th }}$ percentile to its $90^{\text {th }}$ percentile approximately doubles the probability for a rockfall event under median sub-surface moisture conditions. When the moisture content of the ground is at its $95^{\text {th }}$ percentile the same increase in precipitation leads to a four-fold increase in rockfall probability. The occurrence of a freeze-thaw cycle in the preceding days can further increase the rockfall hazard. The most critical combination can be expected in the winter season after a freeze-thaw transition which is followed by a day with high precipitation amounts and takes place in a region preconditioned by a high level of sub-surface moisture.

\section{Introduction}

Landslides are geomorphological hazards associated with damage and fatalities to people and their connected structures (Froude and Petley, 2018). There is scientific consensus that specific weather conditions can strongly influence landslide 
occurrences (McColl, 2015). Thus, as effects of climate change become more and more visible, the scientific community tries to understand and predict the consequences for landslides (e.g., Gariano and Guzzetti, 2016; Macciotta et al., 2017; Haque et al., 2019; Bajni et al., 2021). However, specific weather conditions must meet specific ground conditions for landslides to occur. Consequently, meteorological parameters and thresholds are spatially heterogeneous and results from previous studies on this issue site-specific. Furthermore, the term "landslides" encompasses multiple mass wasting processes on slopes (e.g., mud flow and rockfall) that each depend on different preconditions and trigger mechanisms (Varnes, 1978; Hungr et al., 2014). It is therefore sensible to study these different types of processes separately.

Against this background, the present study focuses on multiple rockfall clusters spanning over all of Germany. Rockfall is the removal of superficial and individual rocks from a rock cut slope (Robbins et al., 2021). In solid rock, frequency and size of fissures and cracks are preconditions that promote rockfall, i.e., they represent weak points vulnerable to weathering that may eventually dislodge individual rocks (Erismann and Abele, 2001). Thus, all weathering mechanisms that promote rockfall can also be trigger mechanisms that cause the start of a rockfall event. Weathering mechanisms driven by meteorological events can be the wetting and drying of porous (esp. argillaceous) rocks from precipitation and evaporation, carbonate dissolution in carbonic rocks from rainfall, and frost shattering from low temperatures (Souleymane et al., 2008; Krautblatter et al., 2012; Viles, 2013). In case of frost shattering, weathering and triggering mechanisms may differ, since rockfalls may occur during thawing rather than during cooling periods because the cohesion of the ice-rock interface can be sufficient to hold the rock in place (D'Amato et al., 2016). Moreover, there are weathering mechanisms not directly linked to meteorological events that may promote or trigger rockfalls. Tectonic activity may weather rock through phases of folding, thrusting, strike-slip, and normal faulting (Di Luzio et al., 2020). Tree root growth may expand rock fractures and joints (Dorren et al., 2007). Lastly, anthropogenic induced vibrations and tremors (e.g., from explosions or machine use) or direct constructional interventions may lead to weathering of rock (Gill and Malamud, 2017).

In this context, the question arises whether a statistical model focused on meteorological parameters can accurately predict rockfall occurrence. A first investigation conducted on a monthly basis by Rupp and Damm (2020) already suggests that a relationship between rockfall events, temperature and precipitation is likely to exist in the selected study areas. The present analysis focuses on the quantification of these effects. To allow for the application of the results in climate change studies, it is essential to consider all climatic factors which promote or suppress rockfall together as they can reinforce or cancel each other (Crozier, 2010). For example, climate projections suggest that rockfall promoter and trigger heavy precipitation may increase in magnitude and frequency due to the higher moisture holding capacity of warmer air (IPCC, 2012). At the same time, increases in evaporation due to higher temperatures decreases water availability, thus slowing down weathering mechanisms. To account for this, a statistical model which includes the interaction between the relevant variables was developed. In the following, a logistic regression model describing the probability of rockfall events in Germany in response to meteorological and hydrological conditions is presented. 


\section{Data}

\subsection{Rockfall}

The present study uses historical rockfall data which are extracted from the landslide database of Germany (cf. Damm and Klose, 2015; Rupp and Damm, 2020). Scientific publications, governmental reports, police reports, civil protection reports, newspapers, field data collections as well as GIS and web analyses were the vital information sources for the landslide database which currently contains about 6000 mass movement events of different types. The database mainly covers a period of about the last 200 years, with the oldest event dated to 1137. Information on 670 rockfall events (Fig. 1) are collocated in the rockfall dataset. The focus of the present study is on a number of geomorphological processes (e.g. rockfall, rock topple, debris fall, debris topple) that are characterised by the rapid gravitational downslope fall of debris or rocks (Whalley, 1974; Varnes, 1978; Flageollet and Weber, 1996; Sass and Oberlechner, 2012). Due to the different particle sizes and volumes of the detached masses, the mentioned processes are subsumed under the generic term rockfall in this study (Evans and Hungr, 1993; Selby, 1993). Beside an identification number, the location (i.e. coordinates) and the year of occurrence for each rockfall event are stored in the dataset. A total of 642 rockfalls has the year of occurrence, as the remaining are undated. The time span of rockfall occurrences ranges between 1480 and 2018, with the greater number $(n=621)$ from 1873 onwards. The dense spatial clustering of rockfall events and high temporal data homogeneity set the selection of three study areas (ES = German part of the Elbe Sandstone mountains, HL = northern Hesse and southern Lower Saxony, HR = western Hesse and Rhineland-Palatinate) (Fig. $1)$.

\subsubsection{Elbe Sandstone cluster}

The ES cluster mainly includes the German parts of the Elbe Sandstone Mountains which are located on both sides of the upper reach of the river Elbe between the Czech city Děčín and the Saxon city Pirna. Geologically, the area is dominated by compact Cretaceous sandstones. Fracturing and formation of cracks and fissures came about by extensive uplift processes and long-term tectonic stresses. Fluvial incision accounted for a heavily dissected relief with numerous horizontal cracks, vertical joints and clefts as well as small gorges (Pälchen and Walter, 2008). The climatic conditions are characterised as continental, with warm summers and cold winters. The mean monthly temperature is between $-0.8^{\circ} \mathrm{C}$ in January and $17.8^{\circ} \mathrm{C}$ in July. Between 1946 and 2017 annual precipitation ranges between $398 \mathrm{~mm}$ and $1153 \mathrm{~mm}$ with an annual average of $758 \mathrm{~mm}$.

\subsubsection{Hesse and Lower Saxony cluster}

The HL cluster imbeds large parts of the northern German Central Uplands, i.e. the Hesse Highlands and Lower Saxon Hills. Predominantly, the geological conditions are characterised by Middle Lower Triassic Bunter Sandstone. Pronounced dissections were caused by tectonic stresses (Damm et al., 2010). Quaternary sediments, for example periglacial cover beds and loess covers, cover the bedrock in large parts of the area (Wagner, 2011; Damm et al., 2013). The climatic situation can be described 
as temperate with warm summers and mild winters. The mean monthly temperature is between $0.5^{\circ} \mathrm{C}$ in January and $17.3^{\circ} \mathrm{C}$ in July. From 1902 to 2017 annual precipitation ranges between $357 \mathrm{~mm}$ and $1099 \mathrm{~mm}$ with an annual average of $660 \mathrm{~mm}$.

\subsubsection{Hesse and Rhineland-Palatinate cluster}

The HR cluster comprises large parts of the Hunsrück Hills in Rhineland-Palatinate and a small part of the Taunus Hills in Hesse. Geologically, Devonian bedrock, namely slate and quartzite, is predominantly present in this area. Distinct plateaus alternate with ridges and incised valleys (LBG, 2005). The climatic situation can be described as temperate, with mild winters and warm summers. The mean monthly temperature is between $1.4^{\circ} \mathrm{C}$ in January and $18.4^{\circ} \mathrm{C}$ in July. Between 1915 and 2017 annual precipitation ranges between $324 \mathrm{~mm}$ and $853 \mathrm{~mm}$ with an annual average of $641 \mathrm{~mm}$.

It is important to note that the rockfall database is not comprehensive. The increase in the number of recorded events with time (Fig.2) is not due to climatic conditions but reflects the fact that data on rockfall events was more readily available in recent years.

\subsection{Meteorological and hydrological variables}

For this study, datasets with a long record and high horizontal resolution were used in order to identify meteorological and hydrological conditions for as many rockfall events as possible with sufficient accuracy. It was therefore decided to use the gridded REGNIE dataset (Rauthe et al., 2013) for daily precipitation amounts. The dataset is compiled from spatially interpolated gauge measurements of the quality-controlled German weather service (DWD) stations. REGNIE is available since 1931 for western Germany. For the new federal states the time series starts in 1951 . The spatial resolution is $1 \mathrm{~km}^{2}$.

In order to study precipitation intensities, data from the gridded radar based climatology RADKLIM (Winterrath et al., 2018) was used. The dataset includes hourly precipitation from radar measurements adjusted to station observations and exhibits a horizontal resolution of $1 \mathrm{x} 1 \mathrm{~km}$. For the present study the daily maximum was extracted. The time series is comparatively short as it only starts in 2001.

For temperature it was decided to use the gridded E-OBS dataset (Cornes et al., 2018) as it goes back until the year 1950. The horizontal resolution of the grid is $0.1^{\circ} \times 0.1^{\circ}$, which corresponds to approximately $8 \mathrm{~km}$ in Germany. For the analysis of freezethaw cycles the ensemble mean of near-surface atmospheric daily minimum and daily maximum temperatures provided in the v21.0e version of the dataset was used. A freeze-thaw cycle was defined as the transition from a daily minimum temperature below $-1^{\circ} \mathrm{C}$ to a daily maximum temperature higher than $0^{\circ} \mathrm{C}$.

The water content of the ground (e.g. soil moisture, cleft water, water in rock pores) is measured only at very few sites. Soil moisture monitoring in Germany, for example, relies on modelled soil moisture (Zink et al., 2016). In this study we attempt to utilise modelled soil moisture as a representative for all types of sub-surface water and will use the term pore water in the following. We analyse the results of a simulation with the state-of-the-art, grid-based hydrological model mHM (Samaniego et al., 2010), which was calibrated using gauge measurements. The set-up is based on European datasets as described in Rakovec et al. (2016) and Samaniego et al. (2019). We analysed the relative moisture content (i.e. degree of saturation) for the 


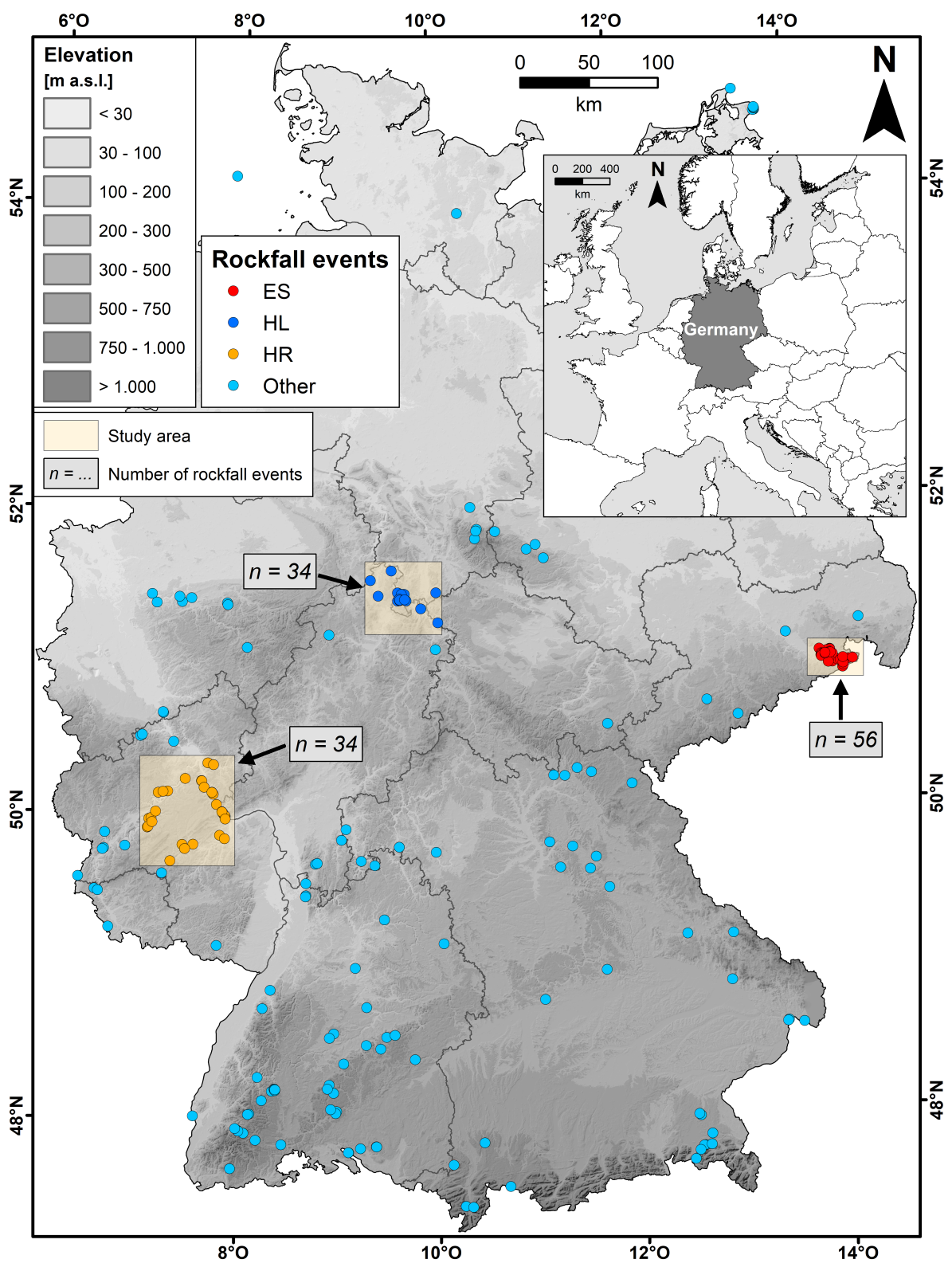

Figure 1. Location of rockfall events analysed in this study. Three distinct clusters are marked in red, blue and orange. All other events are coloured in light blue.

entire column from the surface to a depth of approximately $1.8 \mathrm{~m}$. It is common practice for this model to further normalise these values using percentiles (Zink et al., 2016) as the variability of the modelled values is too low.

A challenging point of using simulated soil moisture is, that it is operationally available only for a part of climate scenario simulations. In addition, the moisture variables stored and the levels they represent differ between climate models. Therefore, 


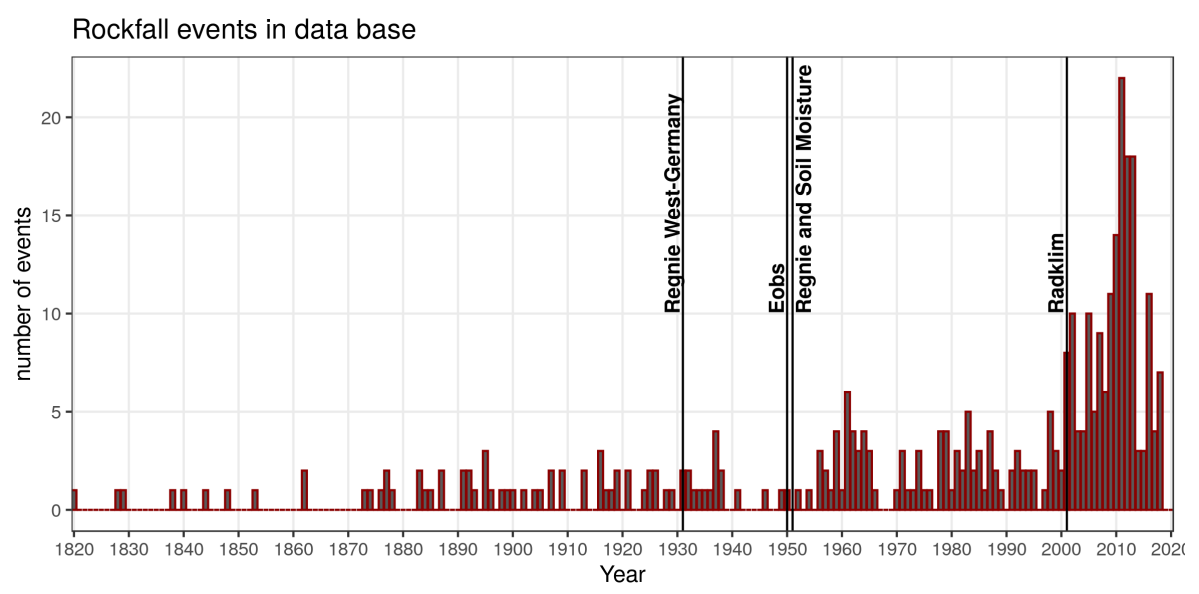

Figure 2. Time series of the number of rockfall events per year included in the data base. The years at which the meteorological and hydrological observations start are indicated.

the usage of a pore water proxy $(D)$ as an alternative to simulated soil moisture was tested as a predictor for the logistic regression model. $D$ is defined as the difference between precipitation accumulated over a period of time $\left(P r e c_{a c c u m}\right)$ and the potential evapotranspiration $(P E T)$ during this period:

$D=$ Prec $_{a c c u m}-$ PET

The term $D$ is also the basis for the calculation of the Standardised Precipitation Evapotranspiration Index (SPEI; VicenteSerrano et al., 2010), which includes a standardisation of $D$ in order to allow comparisons between different climatic regions, which is not necessary here. Plenty of empirical methods exist to determine potential evaporation and it depends on the availability and quality of the observations available at a site which one can be used. In this study, the method first proposed by Hargreaves (1994) in the version modified by Droogers and Allen (2002) was applied. As input parameters it needs extraterrestrial radiation (which depends on latitude and day of the year), the period mean of maximum and minimum daily temperatures, as well as mean precipitation over the period of interest (which is used as a proxy for cloudiness). Thus, $D$ does not depend on the material of the ground. In order to use $D$ as a proxy for pore water it was accumulated over a period of time. Different accumulation periods were compared and the best result was obtained using a weekly period.

The following analyses include only data from grid boxes that contain the site (es) of at least one rockfall event. This approach ensures that regions without any predisposition (e.g. flat terrain, no rocks) don't obscure the results. Grid boxes that contain locations of rockfall events that took place before the start or after the end of the respective record are also not considered. 


\section{Selection of potential predictors}

In order to analyse their potential to influence rockfall probability all variables were screened individually using weight of evidence (WOE), which is defined as the logarithm of the Bayes factor (Good, 1985; Neuhäuser and Terhorst, 2007).

$W O E=\ln \frac{f(X \mid Y=1)}{f(X \mid Y=0)}$,

where $X$ is the independent variable and $Y$ is the binary information if the event occurred. $f(X \mid Y)$ denotes the conditional probability density function for $\mathrm{X}$ if $\mathrm{Y}$ is true $(=1)$ or false $(=0)$. In practice, a continuous independent variable (e.g. precipitation amount) is split into bins containing a range of values. The WOE for each bin is then calculated using only days within this range. The WOE depends on the fraction of days with a rockfall event to that of uneventful days. For categorical variables the WOE is determined for each category.

$W O E_{b}=\ln \left(\frac{\% \text { NoRockfall }_{b}}{\% \text { Rockfall }_{b}}\right)$

A graphical inspection of the result (Fig. 3) already reveals if a relationship between the independent variable and the probability of rockfall exists. An integral measure for the strength of the relationship between the dependent and independent variable is the Information Value (IV; Siddiqi, 2006). It is calculated as

$I V=\sum_{b=1}^{\text {nbins }}\left(\%\right.$ NoRockfall $\left._{b}-\% \operatorname{Rockfall}_{b}\right) \times W O E_{b}$

with nbins being the number of bins. According to Siddiqi (2006) a predictor is not useful for statistical modelling if the IV value is less than 0.02 .

The IV can also be used to rank the variables according to their influence. The highest IV is obtained for daily precipitation followed by precipitation intensity, soil moisture and freeze-thaw cycles. To take into account that the thawing process might take several days, a time span preceding the event was evaluated. Comparing different time spans, it turned out that the IV value associated with a freeze-thaw cycle immediately before the rockfall event (i.e. preceding 2 days) was too low to be considered useful for statistical modelling. Extending the analysis period backward in time increased the IV value, with the increase flattening out after 9 days. The WOE analysis also confirmed that in accordance to the findings of D'Amato et al. (2016) thawing increases rockfall probability while freezing decreases it (not shown). It should be noted, that in the evaluation depicted in Fig. 3 the number of rockfall events and grid boxes included in the WOE calculations differ depending on the length and spatial resolution of the respective meteorological/soil moisture datasets. A consistency test reducing the number of grid boxes, time steps and events to the subset covered by all datasets (not shown) confirms the ranking.

It is important to keep in mind that, despite the name of the analysis, a statistical relationship is no prove for a cause and effect relationship. As rockfall occurrence in Germany exhibits a seasonal cycle with a maximum in January (Rupp and Damm, 2020) it is easy to establish a statistically significant but physically incoherent relationship to any unrelated variable with a similar seasonal cycle. To account for this problem, we only analysed variables for which a physical relationship to rockfall events has already been established in previous studies for other sites. 
(a)

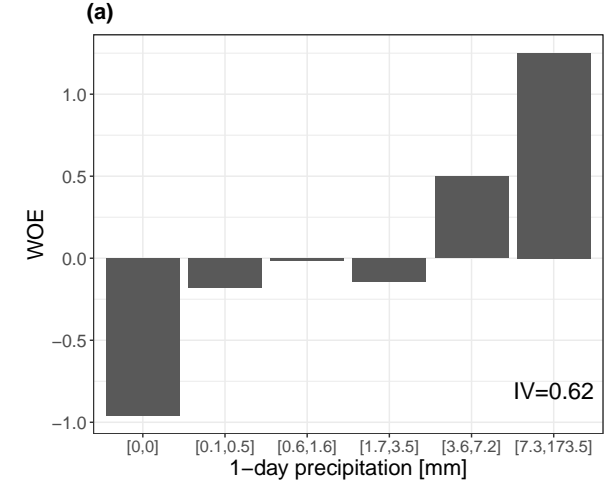

(c)

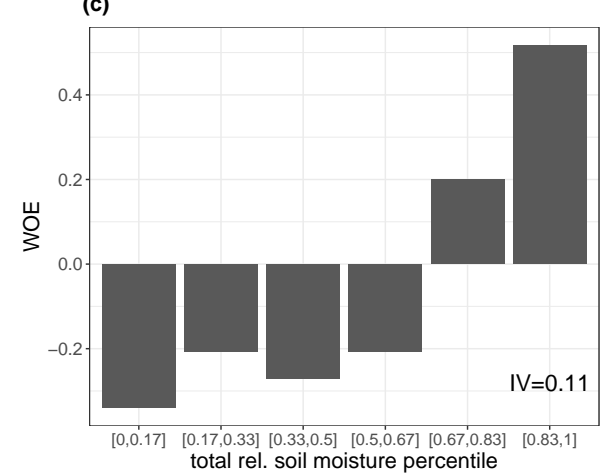

(b)

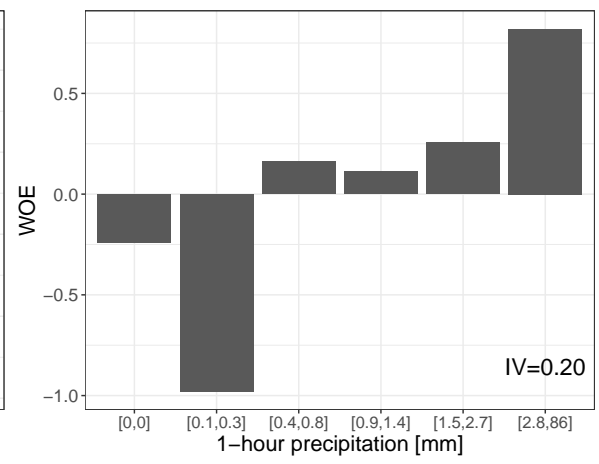

(d)

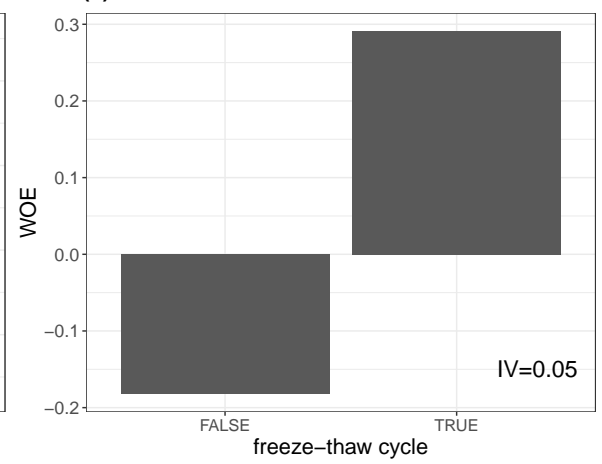

Figure 3. Weight of evidence (WOE) for a) daily precipitation, b) hourly precipitation, c) percentile of relative simulated soil moisture content over all layers d) occurrence of a freeze-thaw cycle in the previous 9 days

\section{Construction of a statistical model}

A well established statistical method to determine probabilities for a binary event (e.g. rockfall vs. no rockfall) based on the conditions of independent variables is logistic regression. Here, a logistic regression model using precipitation, pore water and freeze-thaw cycles as independent meteorological and hydrological variables is fitted. The consideration of individual rockfall clusters (section 2.1) provides information on possible regional differences of the results.

To fit the logistic regression model we used as many data points $n=e s * t s$ as possible, with $t s$ being the the number of days for which meteorological/hydrological data is jointly available among all variables used as independent parameters in the model. The number of event sites (es) at which a rockfall event was recorded within the period covered by the meteorolog$\mathrm{ical} /$ hydrological observations depends on $t s$. Other than for the WOE analysis, we neglected the fact that some grid boxes enclose the site of more than one event. As the grouping of the events depends on the resolution of the individual datasets included in the statistical model, this was necessary to allow a comparison of the different models. Evaluations involving precipitation intensity are carried out based on a much shorter period and a lower number of sites than all other evaluations, which will be considered when comparing the results. 
For logistic regression a generalised linear model with a logit link function is fitted (Wilks, 2011). The probability $p_{k}$ of a rockfall event at a specific time and location can be expressed as

185

$p_{k}=\frac{1}{1+\exp \left(-b_{0}-b_{1} x_{1}-\ldots-b_{i} x_{i}\right)}$

$\left(x_{1}, \ldots, x_{i}\right)$ are the predictors (i.e. meteorological/hydrological variables at the chosen time and location) and $\left(b_{0}, b_{1} \ldots, b_{i}\right)$ are the regression coefficients, which we determined with the glm-function of the statistical software R (R Core Team, 2018).

The classical score to compare logistic regression models of different complexity is the Brier skill score which, however, becomes unstable for rare events such as ours (Benedetti, 2010). We therefore use the logarithmic skill score (LSS) instead, which behaves similar to the Brier skill score but performs better for extreme probabilities (Benedetti, 2010; Wilks, 2011). The logarithmic skill score quantifies the percentage gain of using the statistical model over just predicting the climatological probability and is calculated as follows:

$L S S=1-\frac{L S}{L S_{\text {clim }}} * 100 \%$

where $L S=\frac{1}{n} \sum_{k=1}^{n} L S_{k}$ is the logarithmic score. The value of $L S_{k}$ is determined for each day and location using the probabilities $p_{k}$ calculated by the logistic regression model for the corresponding day and site:

$L S_{k}= \begin{cases}-\ln \left(p_{k}\right), & \text { if rockfall event occurs } \\ -\ln \left(1-p_{k}\right), & \text { if rockfall event does not occur }\end{cases}$

$L S_{\text {clim }}$ is calculated analogously using the climatological probabilities $\frac{e s}{n}$ (i.e. one rockfall event at each site).

In order to validate the statistical model and ensure that no overfitting took place it can be tested on a sample of independent data by cross validation. The full event catalogue was divided into 5, approximately equally sized groups with events from the different clusters equally distributed between the groups. The statistical model was then trained using only 4 of the groups and afterwards applied to predict event probabilities in the remaining group. The model is judged by computing the logarithmic scores LS and $\mathrm{LS}_{\text {clim }}$. The process is repeated for all groups and a mean logarithmic skill score is determined (denoted as $\mathrm{LSS}_{c v}$ in Tab.1). In the following analysis LSS $c v$ was used as an objective measure to select the most suitable combination of predictors for modelling rockfall probabilities.

To find the best performing statistical model numerous combinations of the potential predictors were compared. Table 1 lists the results for a selection of these tests. Evaluated predictors include daily precipitation (precip_1day), the local percentile of daily precipitation calculated using wet days (precip_1day_lperc), percentile of simulated total column soil moisture (sm_perc), percentile of parameterised pore water (D_perc), hourly precipitation (precip_1hr), the local percentile of hourly precipitation calculated using wet hours (precip_1hr_lperc), a categorical predictor denoting to which cluster an event belongs (cluster) and a binary predictor indicating if a freeze-thaw cycle occurred at the site during the previous 9 days (ftc). As the full notation of the model equation is space consuming we use the compact symbolic form used in the R programming language (R Core Team, 2018). The operator + denotes adding another predictor term, : marks the product between two predictors while $*$ indicates 
https://doi.org/10.5194/nhess-2021-243

Preprint. Discussion started: 17 August 2021

(c) Author(s) 2021. CC BY 4.0 License.

Table 1. Symbolic formula for a list of logistic regression models tested in this study and main characteristics associated with these models. The characteristics include the number of coefficients that needed to be determined, the number of rockfall events that could be used for fitting, the logarithmic skill score (LSS), the logarithmic skill score determined by cross validation ( $\operatorname{LSS}_{c v}$ ) and the Akaike information criterion (AIC). See text for explanation of symbolic equation notation.

\begin{tabular}{llrrrrr}
\hline & symbolic equation & coefficients & events & LSS & LSS $_{c v}$ & AIC \\
\hline 1 & precip_1day & 2 & 279 & 2.13 & 2.12 & 6189.0 \\
2 & precip_1day_lp & 2 & 279 & 2.97 & 2.96 & 6135.5 \\
3 & sm_perc & 2 & 237 & 0.86 & 0.84 & 5170.7 \\
4 & precip_1hr & 2 & 167 & 0.99 & 0.89 & 3256.6 \\
5 & precip_1hr_lperc & 2 & 167 & 0.87 & 0.69 & 3260.7 \\
6 & precip_1day_lperc+sm_perc & 3 & 237 & 3.83 & 3.78 & 5018.1 \\
7 & precip_1day_lperc:sm_perc & 2 & 237 & 3.72 & 3.70 & 5021.6 \\
8 & precip_1day_lperc*sm_perc & 4 & 237 & 3.94 & 3.89 & 5014.1 \\
9 & (precip_1day_lperc:cluster)+(sm_perc:cluster) & 9 & 237 & 3.98 & 3.83 & 5022.1 \\
10 & precip_1day_lperc*sm_perc*cluster & 16 & 237 & 4.25 & 3.52 & 5021.9 \\
11 & (precip_1day_lperc*sm_perc)+ftc & 5 & 237 & 3.97 & 3.91 & 5014.7 \\
12 & (precip_1day_lperc*sm_perc)+(ftc:cluster) & 12 & 237 & 4.09 & 3.91 & 5020.2 \\
13 & precip_1day_lperc*sm_perc*ftc & 8 & 237 & 4.03 & 3.79 & 5017.5 \\
14 & (precip_1day_lperc*sm_perc)+ftc+precip_1hr & 6 & 139 & 5.59 & 5.11 & 2494.1 \\
15 & (precip_1day_lperc*sm_perc)+ftc & 5 & 139 & 5.59 & 5.24 & 2492.2 \\
16 & (precip_1day_lperc*D_perc)+ftc & 5 & 237 & 4.09 & 4.01 & 5008.2 \\
& & & & & &
\end{tabular}

that all possible combinations of interactions between the predictors are considered. Thus, the term (precip_1day_lperc** D_perc $)+f t c$ in row 16 of Tab. 1 translates to

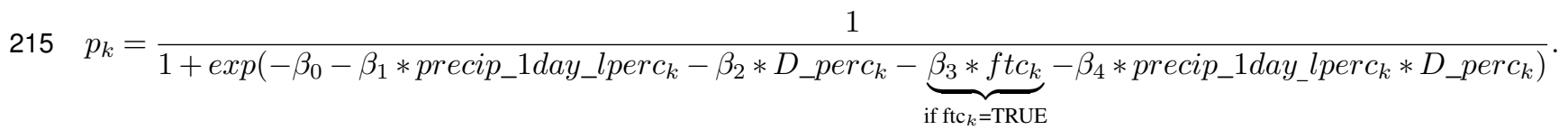

\section{Results}

The performance of the statistical models listed in Tab.1 can be compared with the help of the cross validated logarithmic skill score $\left(\mathrm{LSS}_{c v}\right)$ with a higher skill score denoting a better performance of the model. In addition, the Akaike information criterion can be used to compare two models, which were fitted based on the same number of observations (Akaike, 1974). Here, a lower AIC value is associated with the better model. Comparing models 1-5 confirms that the most important single predictor is daily precipitation which performs best if included in form of its local percentile (denoted by the suffix “_lperc"). 
For hourly precipitation $\operatorname{LSS}_{c v}$ indicates that absolute values lead to better results than local percentiles. The $\operatorname{LSS}_{c v}$ values for soil moisture and for hourly precipitation are of the same magnitude. Models 6-8 reveal that considering soil moisture in addition to the local percentile of daily precipitation improves the statistical model with the best result obtained by using both variables individually as well as their interaction term (model 8). LSS $_{c v}$ can be further increased by adding the binary information of the occurrence of a freeze-thaw cycle in the previous 9 days to the set of predictors (model 11). Adding the binary cluster information (models $9,10,12$ ) has the effect of fitting a separate model to the event clusters. Customising the model to regions, however, does not improve its performance. Model 10 demonstrates the importance of cross validation. This model exhibits the highest number of regression coefficients resulting in a LSS higher than for model 8 . The LSS $\mathrm{L}_{c v}$ is, however, lower than for model 8 indicating that the LSS improvement is achieved by overfitting. At first sight it seems that including hourly precipitation considerably improves the statistical model as the $\mathrm{LSS}_{c v}$ in model 14 is higher than in model 11. It must be kept in mind, though, that the radar climatology is still comparatively short and fits including hourly precipitation are based on a small subset of rockfall events making a direct comparison of $\mathrm{LSS}_{c v}$ and AIC with model 11 impossible. Therefore, the result of model 11 applied to the subset used to fit model 14 is summarised in line 15 of Tab.1. It shows that the increase of LSS $_{c v}$ and decrease of AIC seen for model 14 has to be attributed to the shorter time series and the inclusion of hourly precipitation does not improve the statistical model.

An encouraging result, with respect to facilitating the analysis of climate model output, was obtained when substituting the across-site percentiles of modelled relative soil moisture used in the logistic regression model 11 with across-site percentiles of $D$ (D_perc, Eq. 1). With an accumulation period of 1 week to determine $D \_p e r c$ we obtained the results shown on line 16 of Tab.1. The cross-validated logarithmic skill score of that model is 4.02 , thus model 16 outperforms model 11 . When comparing different accumulation periods for the calculation of $D \_p e r c$ it was found that a 1-week accumulation performs better than a 2-week accumulation period. Across-site percentiles performed better than the absolute values.

In addition to the combinations shown in Tab. 1 it was also investigated if the regression coefficients depend on the slope angle at the event site. For this we downloaded the Copernicus digital elevation model (DEM) at $25 \mathrm{~m}$ horizontal resolution and calculated the slope angle at the rockfall locations using the methodology proposed by Horn (1981). The slopes at the event sites calculated using the DEM data appear plausible at many of the sites. There are, however, also locations for which we determined a slope angle of only few degrees which is inconsistent with the occurrence of rockfall events. A possible explanations could be that the slope was altered by the event and is therefore no longer captured in the DEM dataset representative for the year 2011. In addition, for large-scale rockfall events it is difficult to determine the exact location at which the slope needs to be estimated. Overall, including the slope angle calculated using the DEM as an additional parameter in the logistic regression model did not improve the results.

In summary, Tab. 1 shows that the best results are obtained from the logistic regression model 16 which is expressed in equation 7. The corresponding regression coefficients are $\beta_{0}=-10.57, \beta_{1}=1.1545^{*} 10^{-4}, \beta_{2}=-1.157 * 10^{-2}, \beta_{3}=0.401, \beta_{4}=3.598^{*} 10^{-4}$.

Model 16 (Eq. 7) can now be used to predict changes in rockfall probability valid on average for specified changes of the meteorological conditions and the pore water preconditions. The response of the rockfall probability to variations in the local daily percentile of precipitation and the percentile of the pore water proxy $D$ is depicted in Fig. 4 . With $D$ and local daily precipi- 

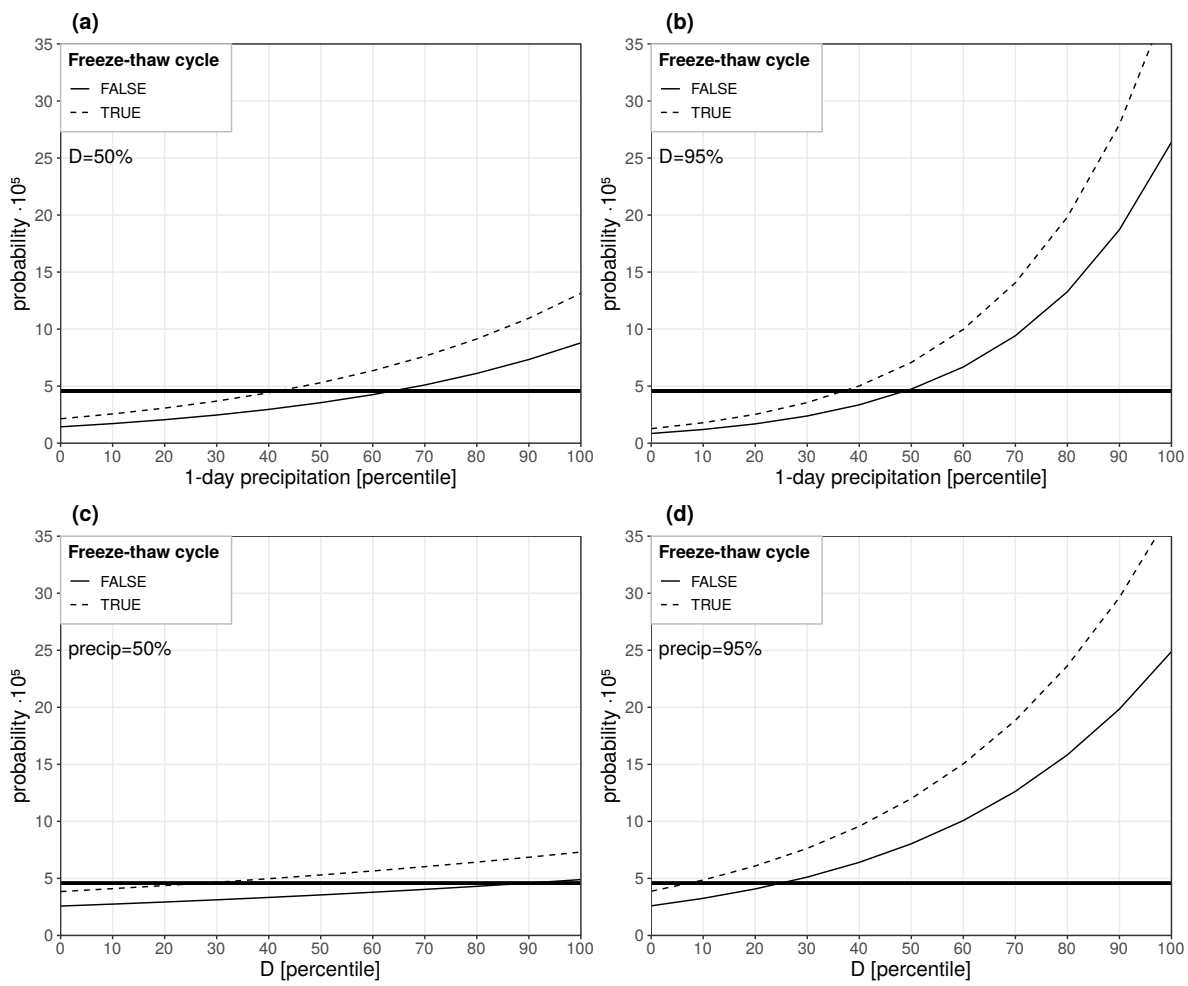

Figure 4. Probability for rockfall predicted by logistic regression model. A dashed/solid curve denotes the result for situations with/without the occurrence of a freezing episode in the previous three weeks. The horizontal line marks the climatological probability. a) Probability as a function of the local percentile of daily precipitation. Constant median (i.e. $50^{\text {th }}$ percentile) of the pore water proxy $D$ (i.e. precipitation minus potential evaporation for the previous 1 -week period). b) Probability as a function of the local percentile of daily precipitation. Constant $95^{\text {th }}$ percentile of $D$. c) Probability as a function of the percentile of $D$. Constant median (i.e. $50^{\text {th }}$ percentile) daily precipitation. d) Probability as a function of the percentile of $D$. Constant $95^{\text {th }}$ percentile daily precipitation.

tation set to median values (Fig. 4a) rockfall events can be expected to appear with approximately climatological probability. Less/more precipitation leads to an below/above climatological average probability. Increasing the local precipitation from the median to its $90^{\text {th }}$ percentile approximately doubles the probability for a rockfall event. The amount of precipitation associated with the $50^{\text {th }}$ percentile varies between 1.2 and $6.8 \mathrm{~mm}$ and that for the $90^{\text {th }}$ percentile between 6.5 and 31.2 depending on the site. The occurrence of a freeze-thaw cycle in the previous days increases the probability for an event. Precipitation becomes more effective when the pore water amount is high (Fig. 4b). When $D$ is at the $95^{\text {th }}$ percentile, increasing precipitation from its median to its 90th percentile makes a rockfall events almost 4 times more likely. The logistic regression model suggests that the influence of pore water on rockfall probability is on average less pronounced than the influence of daily precipitation. At most sites an increase in pore water amount in the absence of strong precipitation has hardly any effect (Fig. 4c). 


\section{Discussion}

In this study a statistical model was developed that is able to describe changes in the probability of rockfall events in Germany that can be expected under different meteorological and hydrological conditions. It must be kept in mind, though, that the rockfall database is not comprehensive. Thus, it cannot be used to calculate an absolute baseline probability. In addition, there is no guarantee that the sampling locations are representative for Germany as a whole. In order to investigate to what extent the model depends on the region that is investigated, we defined three study areas characterised by dense spatial clustering and high temporal data homogeneity and evaluated if the statistical model improves when the regression coefficients are allowed to differ between the clusters (models 9, 10 and 12). It was found that including the cluster information did not improve the model. This provides some reassurance that our approach to develop a statistical model for the entire domain of Germany as well as neighbouring low mountain regions in Central Europe regardless of the different local conditions in different areas was reasonable.

The logarithmic skill score used to evaluate the fit of the statistical model describes the percentage improvement over a model that always predicts a climatological probability for rockfall events. The skill score of our model is just over $4 \%$ and improves to more than 5\% if only the last 20 years are used for model fitting. A value of $4 \%$ appears to be not much, but it has to be interpreted keeping the physics of rockfall events in mind. A rockfall event can only be triggered if the slope is predisposed, after many years of weathering. Because of this, most of the time strong rainfall events in an area with high soil moisture preconditions remains without consequences and the number of false alarms in our model is extremely high. This limitation could only be overcome by including information on the predisposition into the statistical model. Unfortunately, this is not feasible as it would be far too expensive to monitor every slope operationally. Prediction errors (i.e. missed alarms) may steam from events triggered by non-meteorological mechanisms. The model skill obtained using only meteorological/hydrological parameters as predictors, however, suggests that non-meteorological influence seems to be a subordinate factor in the rockfall process for the selected study regions. The improvement of the skill when using only data of the last 20 years could be due to the fact that the rockfall dataset is more comprehensive for the recent past or due to improvements in the quality of meteorological observations.

We found that daily precipitation is the most important factor to trigger rockfall events in Germany. The best fit for the statistical model was obtained when using local percentiles rather than across-site percentiles (not shown) or absolute values. A possible interpretation could be that most rock slopes are balanced under normal climate conditions but can become unstable in the presence of above normal precipitation amounts. Pore water (represented by $D$ or soil moisture) on the other hand leads to better results when across-site percentiles are used. This might be an indication that in most locations pore water on its own is unlikely to trigger a rockfall event. It can weaken porous material making it more susceptible to a trigger like precipitation. This process, however, depends only on the material and not on the climate conditions at the location of the event. The fact that both simulated soil moisture and $D$ improved the statistical model, confirms that these variables can be used as a first-order substitute for all relevant types of sub-surface moisture such as cleft water and water in rock pores. 
https://doi.org/10.5194/nhess-2021-243

Preprint. Discussion started: 17 August 2021

(c) Author(s) 2021. CC BY 4.0 License.

\section{Conclusions}

Using a rockfall dataset for Germany it was possible to build a statistical model which is able to quantify changes in rockfall probability in response to changes in sub-surface moisture and meteorological factors identified in geophysical studies as potential triggers for rockfall events. The model can be regarded as representative for the low mountain ranges in Central Europe.

The model was developed in order to be applied to climate change simulations with the aim of determining if the probability of rockfall events can be expected to change in response to global warming. Applying the statistical model to climate simulation output is facilitated by the fact that the model works with percentiles for most predictors. Thus, only temperature for the evaluation of freeze-thaw cycles needs to be bias corrected. In addition, the complex simulation of soil moisture as a representative for pore water can be substituted by a proxy (i.e. accumulated precipitation minus potential evaporation) which can be easily calculated from climate model output.

For the application in climate change studies it is important that the statistical model considers the interaction between the triggering factors as these are expected to show opposing trends. While heavy precipitation is likely to increase in the future (IPCC, 2012), the number of frost days will decrease with increasing temperatures (IPCC, 2012). Climate projections for aridity in Central Europe depend on location and season (Samaniego et al., 2018). Thus, studies considering only single factors might over or underestimate the response of rockfall to climate change as the interaction of the factors can amplify or diminish the signal.

Data availability. The meteorological data used in this study is freely available. After registration the E-OBS dataset can be be downloaded from https://www.ecad.eu/download/ensembles/ensembles.php. REGNIE is available from |http://opendata.dwd.de/climate_environment/CDC/grids_germany/daily/regnie/and RADKLIM from https://opendata.dwd.de/climate_environment/CDC/grids_germany/hourly/radolan/reproc/2017_002/. Information on the rockfall events can be found in the supporting material of Rupp and Damm (2020). The Copernicus digital elevation model is freely available from https://land.copernicus.eu/imagery-in-situ/eu-dem/eu-dem-v1.1.

Author contributions. KN conducted the statistical analyses and prepared the draft manuscript. SR and BD collected and analysed the rockfall data. SR prepared Fig 1 and provided the rockfall data description. TK wrote the introduction and BG conducted the soil moisture simulations. BD and UU supervised the project and provided advice and feedback in the process.

Competing interests. The authors declare that they have no conflict of interest 
https://doi.org/10.5194/nhess-2021-243

Preprint. Discussion started: 17 August 2021

(C) Author(s) 2021. CC BY 4.0 License.

(c) (1)

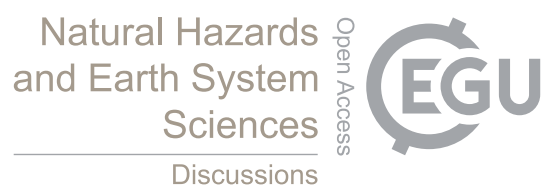

325 Acknowledgements. This study was funded by the Federal Ministry of Education and Research in Germany (BMBF) through the research program ClimXtreme (FKZ: 01LP1903A, 01LP1903K and 01LP1903E) The work used resources of the Deutsches Klimarechenzentrum (DKRZ) granted by its Scientific Steering Committee (WLA) under project IDs b1152 and bm1159. We acknowledge the E-OBS dataset from the EU-FP6 project UERRA (http://www.uerra.eu) and the data providers in the ECA\&D project (https://www.ecad.eu). 
https://doi.org/10.5194/nhess-2021-243

Preprint. Discussion started: 17 August 2021

(c) Author(s) 2021. CC BY 4.0 License.

\section{References}

Akaike, H.: A new look at the statistical model identification, IEEE Transactions on Automatic Control, 19, 716-723, https://doi.org/10.1109/TAC.1974.1100705, 1974.

Bajni, G., Camera, C. A. S., and Apuani, T.: Deciphering meteorological influencing factors for Alpine rockfalls: a case study in Aosta Valley, Landslides, https://doi.org/10.1007/s10346-021-01697-3, 2021.

Benedetti, R.: Scoring Rules for Forecast Verification, Mon. Weather Rev., 138, 203-2011, https://doi.org/10.1175/2009MWR2945.1, 2010.

Cornes, R., van der Schrier, G., van den Besselaar, E. J. M., and Jones, P. D.: Ensemble Version of the E-OBS Temperature and Precipitation Datasets, J. Geophys. Res. Atmos, 123, 10.1029/2017JD028 200, 2018.

Crozier, M.: Deciphering the effect of climate change on landslide activity: A review, Geomorphology, 124, 260-267, https://doi.org/10.1016/j.geomorph.2010.04.009, 2010.

D'Amato, J., Hantz, D., Guerin, A., Jaboyedoff, M., Baillet, L., and Mariscal, A.: Influence of meteorological factors on rockfall occurrence in a middle mountain limestone cliff, Nat. Hazards Earth Syst. Sci, 16, 719-735, https://doi.org/https://doi.org/10.5194/nhess-16-719-2016, 2016.

Damm, B. and Klose, M.: The landslide database for Germany: Closing the gap at national level, Geomorphology, 249, 82-93, https://doi.org/https://doi.org/10.1016/j.geomorph.2015.03.021, 2015.

Damm, B., Becht, M., Varga, K., and Heckmann, T.: Relevance of tectonic and structural parameters in Triassic bedrock formations to landslide susceptibility in Quaternary hillslope sediments, Quatern Int, 222, 143-153, https://doi.org/https://doi.org/10.1016/j.quaint.2010.02.022, 2010.

Damm, B., Terhorst, B., and Ottner, F.: Mid-latitude slope deposits (cover beds), chap. Geotechnical properties of periglacial cover beds,, p. 153, Elsevier, Amsterdam, 2013.

Di Luzio, E., Mazzanti, P., Brunetti, A., and Baleani, M.: Assessment of tectonic-controlled rock fall processes threatening the ancient Appia route at the Aurunci Mountain pass (central Italy), Nat. Hazards, 102, 909-937, https://doi.org/10.1007/s11069-020-03939-4, 2020.

Dorren, L., Berger, F., Jonsson, M., Krautblatter, M., Mölk, M., Stoffel, M., and Wehrli, A.: State of the art in rockfall - forest interactions, Schweizerische Zeitschrift fur Forstwesen, 158, 128-141, https://doi.org/10.3188/szf.2007.0128, 2007.

Droogers, P. and Allen, R. G.: Estimating Reference Evapotranspiration Under Inaccurate Data Conditions,, Irrigation and Drainage Systems, 16(1), 33-45, 2002.

Erismann, T. H. and Abele, G.: Dynamics of Rockslides and Rockfalls, Springer, Berlin, Heidelberg, https://doi.org/10.1007/978-3-66204639-5, 2001.

Evans, S. G. and Hungr, O.: The assessment of rockfall hazard at the base of talus slopes, Can. Geotech. J., 30, 620-636, https://doi.org/https://doi.org/10.1139/t93-054, 1993.

Flageollet, J. C. and Weber, D.: Landslide recognition: identification, movement and causes,, chap. Fall, pp. 13-28, Wiley,, Chichester, 1996.

Froude, M. J. and Petley, D. N.: Global fatal landslide occurrence from 2004 to 2016, Natural Hazards and Earth System Sciences, 18, 2161-2181, https://doi.org/10.5194/nhess-18-2161-2018, 2018.

Gariano, S. L. and Guzzetti, F.: Landslides in a changing climate, Earth-Science Reviews, 162, 227-252, https://doi.org/10.1016/j.earscirev.2016.08.011, 2016.

Gill, J. C. and Malamud, B. D.: Anthropogenic processes, natural hazards, and interactions in a multi-hazard framework, Earth-Science Reviews, 166, 246-269, https://doi.org/10.1016/j.earscirev.2017.01.002, 2017. 
https://doi.org/10.5194/nhess-2021-243

Preprint. Discussion started: 17 August 2021

(c) Author(s) 2021. CC BY 4.0 License.

Good, I. J.: Weight of evidence: A brief survey, Bayesian Statistics, 2, 249-270, 1985.

Haque, U., da Silva, P. F., Devoli, G., Pilz, J., Zhao, B., Khaloua, A., Wilopo, W., Andersen, P., Lu, P., Lee, J., Yamamoto, T., Keellings, D., Wu, J.-H., and Glass, G. E.: The human cost of global warming: Deadly landslides and their triggers (1995-2014), Science of The Total Environment, 682, 673-684, https://doi.org/10.1016/j.scitotenv.2019.03.415, 2019.

Hargreaves, G. H.: Defining and using reference evapotranspiration, Irrigation and Drainage Engineering, 120(6), 1132-1139, https://doi.org/10.1061/(ASCE)0733-9437(1994)120:6(1132), 1994.

Horn, B. K. P.: Hill shading and the reflectance map., Proceedings of the IEEE, 69, 14-47, 1981.

Hungr, O., Leroueil, S., and Picarelli, L.: The Varnes classification of landslide types, an update, Landslides, 11, 167-194, https://doi.org/https://doi.org/10.1007/s10346-013-0436-y, 2014.

IPCC: Climate Change 2013: The Physical Science Basis, Cambridge University Press, Cambridge, United Kingdom and New York, NY, USA, 2012.

Krautblatter, M., Moser, M., Schrott, L., Wolf, J., and Morche, D.: Significance of rockfall magnitude and carbonate dissolution for rock slope erosion and geomorphic work on Alpine limestone cliffs (Reintal, German Alps), Geomorphology, 167-168, 21-34, https://doi.org/10.1016/j.geomorph.2012.04.007, 2012.

LGB (Landesamt für Geologie und Bergbau Rheinland-Pfalz, M., ed.: Geologie von Rheinland-Pfalz, Schweizerbart, Stuttgart, 2005.

Macciotta, R., Hendry, M., Cruden, D. M., Blais-Stevens, A., and Edwards, T.: Quantifying rock fall probabilities and their temporal distribution associated with weather seasonality, Landslides, 14, 2025-2039, https://doi.org/10.1007/s10346-017-0834-7, 2017.

McColl, S. T.: Landslide Causes and Triggers, in: Landslide Hazards, Risks and Disasters, edited by Shroder, J. F. and Davies, T., pp. 17-42, Academic Press, https://doi.org/10.1016/B978-0-12-396452-6.00002-1, 2015.

Neuhäuser, B. and Terhorst, B.: Landslide susceptibility assessment using "weights-of-evidence" applied to a study area at the Jurassic escarpment (SW-Germany), Geomorphology, 86 (1-2), 12-24, https://doi.org/10.1016/j.geomorph.2006.08.002., 2007.

Pälchen, W. and Walter, H., eds.: Geologie von Sachsen I: Geologischer Bau und Entwicklungsgeschichte, Schweizerbart, Stuttgart, 2008.

R Core Team: R: A Language and Environment for Statistical Computing, R Foundation for Statistical Computing, Vienna, Austria, http: //www.R-project.org/, 2018.

Rakovec, O., Kumar, R., Mai, J., Cuntz, M., Thober, S., Zink, M., Attinger, S., Schäfer, D., Schrön, M., and Samaniego, L.: Multiscale and multivariate evaluation of water fluxes and states over European river basins, Hydrometeor., 17, 287-307, https://doi.org/10.1175/JHMD-15-0054.1, 2016.

Rauthe, M., Steiner, H., Riediger, U., Mazurkiewicz, A., and Gratzki, A.: A Central European precipitation climatology - Part I: Generation and validation of a high-resolution gridded daily data set (HYRAS), Meteorol. Z., 22, 235-256, https://doi.org/DOI:10.1127/09412948/2013/0436, 2013.

Robbins, B. A., Stephens, I. J., and Marcuson, W. F.: Geotechnical Engineering, in: Encyclopedia of Geology, edited by Alderton, D. and Elias, S. A., pp. 377-392, Academic Press, second edn., https://doi.org/10.1016/B978-0-12-409548-9.12508-4, 2021.

Rupp, S. and Damm, B.: A national rockfall dataset as a tool for analysing the spatial and temporal rockfall occurrence in Germany, Earth Surf. Process. Landforms, 45, 1528-1538, https://doi.org/10.1002/esp.4827, 2020.

400 Samaniego, L., Kumar, R., and Attinger, S.: Multiscale parameter regionalization of a grid-based hydrologic model at the mesoscale, Water Resour. Res., 46, W05 523, https://doi.org/10.1029/2008WR007327, 2010. 
https://doi.org/10.5194/nhess-2021-243

Preprint. Discussion started: 17 August 2021

(c) Author(s) 2021. CC BY 4.0 License.

(c) (1)

Samaniego, L., Thober, S., Kumar, R., Wanders, N., Rakovec, O., Pan, M., Zink, M., Sheffield, J., Wood, E. F., and Marx, A.: Anthropogenic warming exacerbates European soil moisture droughts, Nature Clim Change, 8, 421-426, https://doi.org/10.1038/s41558-018-0138-5, 2018.

Samaniego, L., Thober, S., Wanders, N., Pan, M., Rakovec, O., Sheffield, J., Wood, E. F., Prudhomme, C., Rees, G., Houghton-Carr, H., Fry, M., Smith, K., Watts, G., Hisdal, H., Estrela, T., Buontempo, C., Marx, A., and R.Kumar: Hydrological forecasts and projections for improved decision-making in the water sector in Europe, Bull. Amer. Meteorol. Soc., 100 (12), 2451 - 2471, 2019.

Sass, O. and Oberlechner, M.: Is climate change causing increased rockfall frequency in Austria?,, Nat. Hazards Earth Syst. Sci.,, 12, 32093216, https://doi.org/doi.org/10.5194/nhess-12-3209-2012, 2012.

410 Selby, M. J., ed.: Hillslope materials and processes, Oxford University Press, New York, 1993.

Siddiqi, N.: Credit Risk Scorecards: Developing and Implementing Intelligent Credit Scoring, Wiley, Hoboken, New Jersey, https://doi.org/10.1002/9781119201731, 2006.

Souleymane, D., Ogawa, Y., and Zhang, M.: Effects of Cyclic Wetting and Drying on Physical and Mechanical Properties of Neogene Sandstones and Siltstones from Boso Peninsula, Japan, Journal of the Japan Society of Engineering Geology, 49, 150-163, https://doi.org/10.5110/jjseg.49.150, 2008.

Varnes, D. J.: Landslides, analysis and control, chap. Slope Movement Types and Processes, pp. 11-33, Transportation Research Board, National Academy of Sciences, Washington, D.C, 1978.

Vicente-Serrano, S. M., Beguería, S., and López-Moreno, J. I.: A multi-scalar drought index sensitive to global warming: the standardized precipitation evapotranspiration index - SPEI, J. Clim., 23, 1696- 1718, https://doi.org/10.1175/2009JCLI2909.1, 2010.

Viles, H. A.: Linking weathering and rock slope instability: non-linear perspectives, Earth Surf. Process. Landforms, 38, 62-70, https://doi.org/10.1002/esp.3294, 2013.

Wagner, B.: Spatial analysis of loess and loess-like sediments in the Weser-Aller catchment (Lower Saxony and Northern Hesse, NW Germany),, Quaternary Science Journal, 60(1), 27-46, https://doi.org/doi.org/10.3285/eg.60.1.02, 2011.

Whalley, W. B.: The mechanics of high magnitude-low frequency rock failure and its importance in mountainous areas,, Reading Geographical Papers, 27, 48pp, 1974

Wilks, D. S.: Statistical Methods in Atmospheric Science, Acadamic Press, Oxford, UK, 2011.

Winterrath, T., Brendel, C., Hafer, M., Junghänel, T., Klameth, A., Lengfeld, K., Walawender, E., Weigl, E., and Becker, A.: Reprocessed gauge-adjusted radar-data, one-hour precipitation sums (RW), https://doi.org/10.5676/DWD/RADKLIM_RW_V2017.002,, 2018.

Zink, M., Samaniego, L., Kumar, R., Thober, S., Mai, J., Schäfer, D., and Marx, A.: The German drought monitor, Environ. Res. Lett., 11, $074002,2016$. 